Check for updates

Cite this: RSC Adv., 2018, 8, 21690

Received 21st April 2018

Accepted 28th May 2018

DOI: $10.1039 / \mathrm{c} 8 \mathrm{ra03426e}$

rsc.li/rsc-advances

\section{A novel light diffuser based on the combined morphology of polymer networks and polymer balls in a polymer dispersed liquid crystals film}

\author{
Le Zhou, ${ }^{\mathrm{a}}$ Haipeng Ma, ${ }^{\mathrm{a}}$ Cheng Han, ${ }^{\mathrm{b}}$ Wei Hu, ${ }^{\mathrm{c}}$ Shuaifeng Zhang, ${ }^{\mathrm{b}}$ Lanying Zhang ${ }^{\text {ad }}$ \\ and Huai Yang (iD) *ad
}

A novel light diffuser based on a thermally cured polymer dispersed liquid crystal (PDLC) film was facilely fabricated by the thermal curing of epoxy monomers with thiols and polyamine (PA) in a composite solution of monomers and liquid crystals (LCS) sandwiched by two clean polyethylene terephthalate (PET) substrates. Varied amounts of LCs, diluent effects of epoxy resins and thiols and different curing temperatures have been investigated in the preparation of the films, and the optical properties (total transmittance and transmittance haze) and the light diffusing abilities of these films were also studied. As the microstructures of the polymers in the films were analysed using light scattering theory, it was revealed that the total transmittance of the novel light diffuser, with a combined polymer morphology of polymer networks and polymer balls, can reach $93 \%$ by simultaneously possessing a high transmittance haze (95\%). The novel light diffuser, based on thermally cured PDLCs, possesses a good diffusion capacity and will have promising potential applications in military projects and liquid crystal display (LCDs) devices.

\section{Introduction}

Optical diffusers are essential films that can spatially scatter light sources to prevent light sources from directly being seen by viewers, which are primarily applied in LCDs, LED displays, solar cells and other optical-electrical devices. ${ }^{1-6}$ Recently, two kinds of optical diffusers have been achieved in the LCD field: volumetric types and surface-relief types. ${ }^{1,2}$ The former type is prepared by coating optically transparent substrates with a homogeneous solution, and this solution is made of organic or inorganic particles such as polymethyl methacrylate (PMMA), titanium dioxide $\left(\mathrm{TiO}_{2}\right)$, silicon oxide $\left(\mathrm{SiO}_{2}\right)$, cerium dioxide $\left(\mathrm{CeO}_{2}\right)$, polystyrene (PS), etc., polymers and an optimum solvent. ${ }^{2-13}$ However, the fatal problem that exists in this type is the dispersion of particles, which depends on the complex preparation of the particles. ${ }^{1}$ To overcome the difficulties, optical diffusers based on boehmite hollow microspheres, ${ }^{1}$ hollow silica nanoparticles, ${ }^{3}$ core-shell-like scatterers, ${ }^{5}$ strawberry-like polymethyl methacrylate $/ \mathrm{SiO}_{2}$ composite

\footnotetext{
${ }^{a}$ Department of Materials Science and Engineering, College of Engineering, Peking University, Beijing 100871, People's Republic of China. E-mail: yanghuai@pku.edu.cn ${ }^{b}$ Department of Materials Physics and Chemistry, School of Materials Science and Engineering, University of Science and Technology Beijing, Beijing 100083, People's Republic of China

${ }^{c}$ Department of Chemistry and Chemical Engineering, School of Chemistry and Biological Engineering, University of Science and Technology Beijing, Beijing 100083, People's Republic of China

${ }^{d}$ Key Laboratory of Polymer Chemistry and Physics of Ministry of Education, Peking University, Beijing 100871, People's Republic of China
}

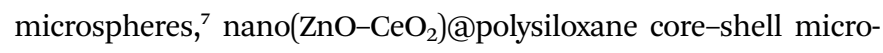
spheres, ${ }^{10}$ hybrid polysiloxane@ $\mathrm{CeO}_{2} @ \mathrm{PMMA}^{11}$ and $\mathrm{ZnO@poly-}$ siloxane microspheres ${ }^{12}$ have been explored in detail and their optical properties have been greatly improved. Additionally, Simonutti et al. have designed a controlled light diffuser by doping ppm concentrations of commercial $\mathrm{TiO}_{2}$ nanoparticles into PMMA plate. ${ }^{14}$ The latter type is based on special interfacial microstructures such as pyramids, microlenses and other microstructures in order to obtain uniform light, and presents the advantages of wide-viewing and high contrast, while most of the microstructures are complex and are produced by expensive equipment. ${ }^{15,16}$ Recently, Butt et al. were the first to introduce willemite into optical diffusers, which enabled light beams to be widely spread, while transmission of the optical diffuser was influenced by its high scattering. ${ }^{17-22}$

PDLC films are films that have LCs randomly dispersed in a polymer matrix, of which the polymer is formed by thermal curing or ultraviolet curing of curable monomers such as epoxy resins and acrylate monomers. ${ }^{23-25}$ Polymer morphologies in the films can be divided into polymer-network-type and polymerball-type. ${ }^{26-28}$ By optimizing the light scattering performance, PDLC films with high transmittance can be applied in solar cells, organic light emitting diodes (OLEDs) and other optical electrical devices. Yang et al. have demonstrated a novel light enhancing film based on PDLCs that can increase the light efficiency of OLEDs. ${ }^{29}$

At present, more attention is focused on thermal polymerization with dispersed LCs. Epoxy resins have become one of the 
most effective sources for fabricating PDLC films, due to their straightforward curing process. An epoxy diluent monomer has been utilized in our system, as epoxy resins have large viscosity. Additionally, thiols were used as a novel accelerant for the curing agent PA in the optimization of the reaction process of the epoxy resin. In this work, both a polymer-network type film and a polymer-ball type film were obtained by varying the concentrations of LCs, epoxy diluent monomers and thiols as well as the curing temperatures, and the optical properties of the films were investigated.

\section{Experimental}

\subsection{Materials}

Fig. 1 shows the chemical structures of the components, including E-51 type epoxy resin, resorcinol diglycidyl ether (RDE), trimethylolpropane tris(3-mercaptopropionate) (TTMP) and polyamide (PA). RDE (purchased from Heowns Biochem Technologies) is used as an epoxy monomer and a reactive diluent in the presence of E-51 type epoxy resin. PA (purchased from Beijing Chemical Co. Ltd) is utilized as a room temperature curing agent and a macromolecule with repeating units linked by amide bonds. TTMP is a thiol with ester bonds, which is produced by Heowns Biochem Technologies. SLC1717 is a nematic LC mixture (TNI $=365 \mathrm{~K}, \Delta n=0.201, n_{\mathrm{o}}=1.519, n_{\mathrm{e}}=$ 1.720), which was provided by Shijiazhuang Chengzhi Yonghua Display Materials Co. Ltd. All the materials were used as received without any further purification.

\subsection{Preparation of films T1-T3, L1-L5, R1-R6 and P1-P5}

Composite films L1-L5, R1-R6, P1-P5 and T1-T3 were respectively prepared by the quantified mixture of E-51, RDE, TTMA, PA and SLC1717 as shown in Table 1, and then vigorously stirred and sonicated for 5 min to form a homogeneous solution. The composite solution was injected between two pieces of PET substrate based on the capillary effect, and was cured in an oven at defined temperatures for $1 \mathrm{~h}$. The thickness of all of these films was controlled by $20 \mu \mathrm{m}$ thick glass beads. All the films were cured at $333.15 \mathrm{~K}$ with the exception of film T1 (at $313.15 \mathrm{~K}$ ) and film T3 (at $353.15 \mathrm{~K}$ ). Films T1, T2 and T3 were prepared with the same composition but cured at different temperatures. The content of LC in samples L1-L5 varied from $30 \mathrm{wt} \%$ to $70 \mathrm{wt} \%$ at intervals of $10 \mathrm{wt} \%$ while keeping the
Table 1 The compositions of PDLC films

\begin{tabular}{lll}
\hline Sample ID & E-51/RDE/TTMP/PA/LC $(w t \%)$ & $\begin{array}{l}\text { Curing } \\
\text { temperature }(\mathrm{K})\end{array}$ \\
\hline T1 & $6.25 / 18.75 / 6.25 / 18.75 / 50$ & 313.15 \\
T2 & $6.25 / 18.75 / 6.25 / 18.75 / 50$ & 333.15 \\
T3 & $6.25 / 18.75 / 6.25 / 18.75 / 50$ & 353.15 \\
L1 & $8.75 / 26.25 / 8.75 / 26.25 / 30$ & 333.15 \\
L2 & $7.5 / 22.25 / 7.5 / 22.65 / 40$ & \\
L3 & $6.25 / 18.75 / 6.25 / 18.75 / 50$ & \\
L4 & $5 / 15 / 5 / 15 / 60$ & \\
L5 & $3.75 / 11.25 / 3.75 / 11.25 / 70$ & \\
R1 & $0 / 25 / 6.25 / 18.75 / 50$ & \\
R2 & $5 / 20 / 6.25 / 18.75 / 50$ & \\
R3 & $6.25 / 18.75 / 6.25 / 18.75 / 50$ & \\
R4 & $18.75 / 6.25 / 6.25 / 18.75 / 50$ & \\
R5 & $20 / 5 / 6.25 / 18.75 / 50$ & \\
R6 & $25 / 0 / 6.25 / 18.75 / 50$ & \\
P1 & $6.25 / 18.75 / 0 / 25 / 50$ & \\
P2 & $6.25 / 18.75 / 5 / 20 / 50$ & \\
P3 & $6.25 / 18.75 / 6.25 / 18.75 / 50$ & \\
P4 & $6.25 / 18.75 / 18.75 / 6.25 / 50$ & \\
P5 & $6.25 / 18.75 / 20 / 5 / 50$ &
\end{tabular}

concentration of the other chemicals at a fixed ratio. The weight ratio of monomer E-51 and monomer TTMP was $1: 1$, the weight ratio of monomer E-51 and monomer RDE was $1: 3$, and the weight ratio of monomer TTMP and monomer PA was also $1: 3$. For samples R1-R6, the total content of monomer E-51 and RDE was $25 \mathrm{wt} \%$ and the content of the other chemicals was at a fixed ratio, but the concentration of monomer E-51 was varied from 0 to $25 \mathrm{wt} \%$. While in samples P1-P5, the total content of monomer TTMP and PA was $25 \mathrm{wt} \%$ and the content of the other chemicals was at a fixed ratio, but the concentration of monomer TTMP was varied from 0 to $25 \mathrm{wt} \%$.

\subsection{Characterization}

The total transmittance and transmittance haze of the prepared films were examined using a UV-vis-NIR spectrophotometer (America, PE Lamda 950) in the visible region (400-800 nm). The UV-vis-NIR spectra of the films were obtained in compliance with ASTM D1003 by adding an integrating sphere device. The optical diffusion abilities of the films were measured by a light intensity distribution measuring instrument (HP860 LED luminous intensity

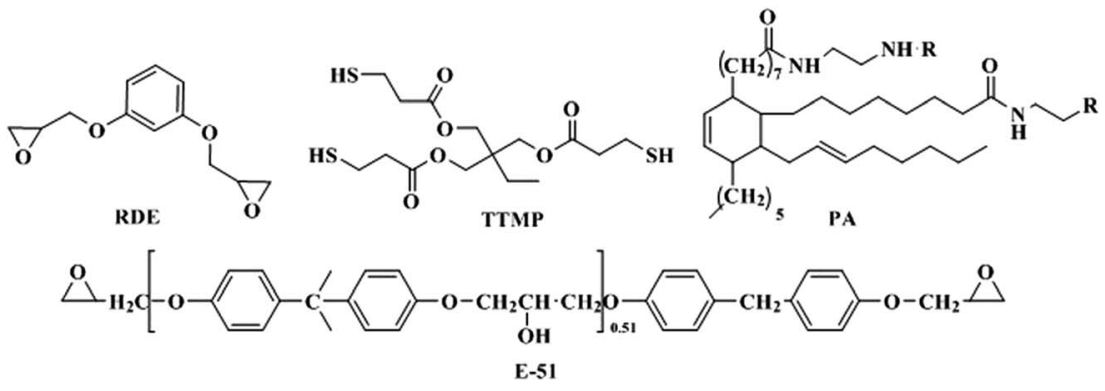

Fig. 1 Chemical structures of RDE, TTMP, PA and E-51. 

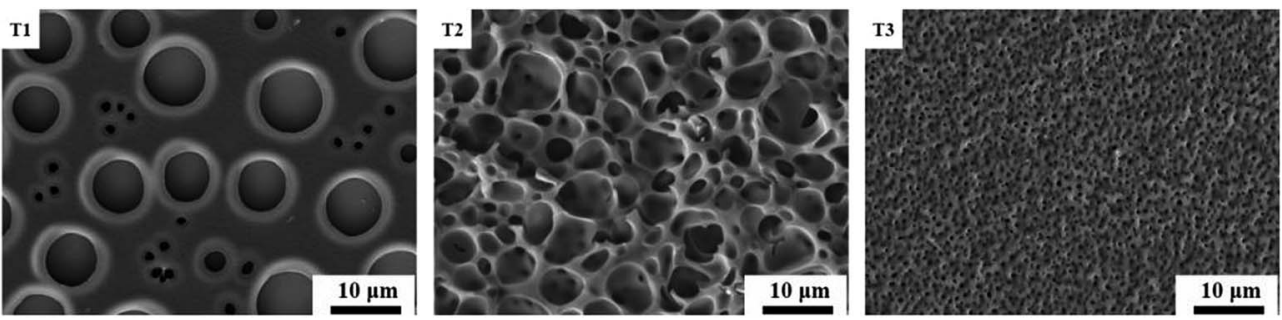

Fig. 2 SEM micrographs of the polymer morphologies of films T1-T3.

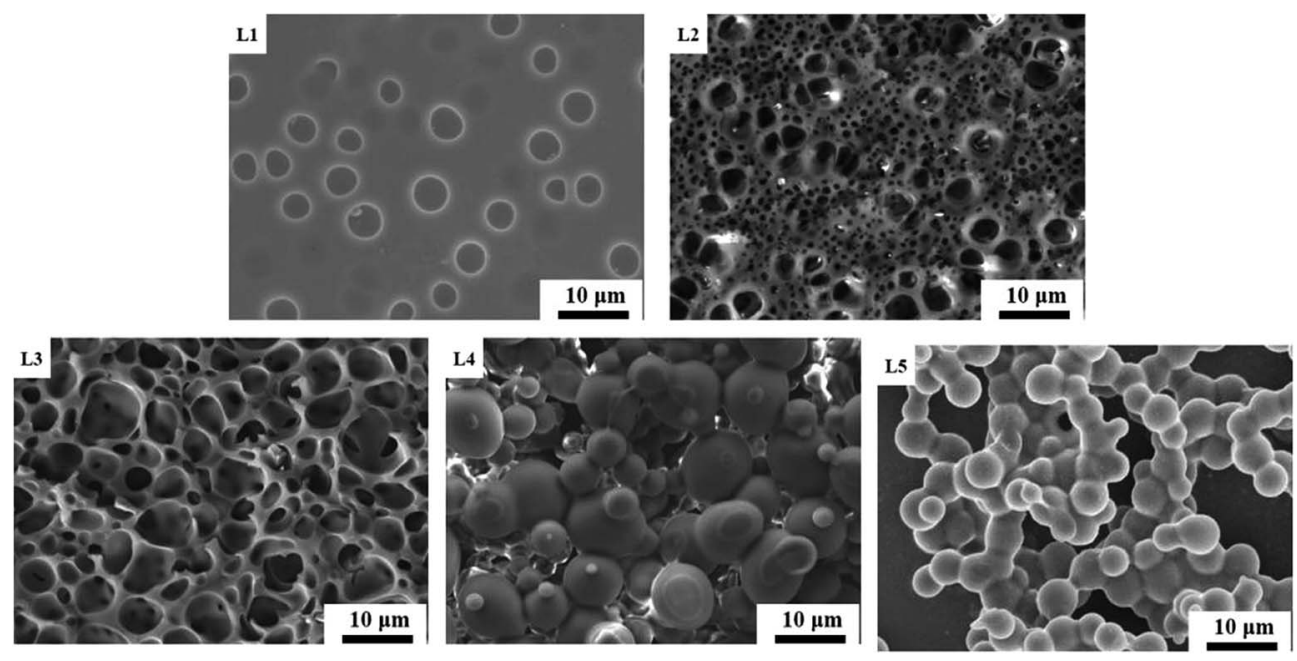

Fig. 3 SEM micrographs of the polymer morphologies of films L1-L5.

distribution tester) which was designed by Hongpu optoelectronics technology Co. LTD and by members of our lab. The films were illuminated by a perpendicular collimated beam using a He-Ne laser and having a divergence of $\pm 0.5^{\circ}$, of which the light wavelength was $560.0 \mathrm{~nm}$ and the beam diameter was $2.0 \mathrm{~mm}$. The distance between the films and the light source was $4.0 \mathrm{~cm}$, while the distance between the photodetector and the films was $40.0 \mathrm{~cm}$. The films and the light source synchronously rotated from -60.0 degrees to 60.0 degrees and the detector recorded the corresponding light intensity. Additionally, the size of the measured films were all $5 \mathrm{~cm} \times 5 \mathrm{~cm}$ (length $\times$ width). The morphologies of the
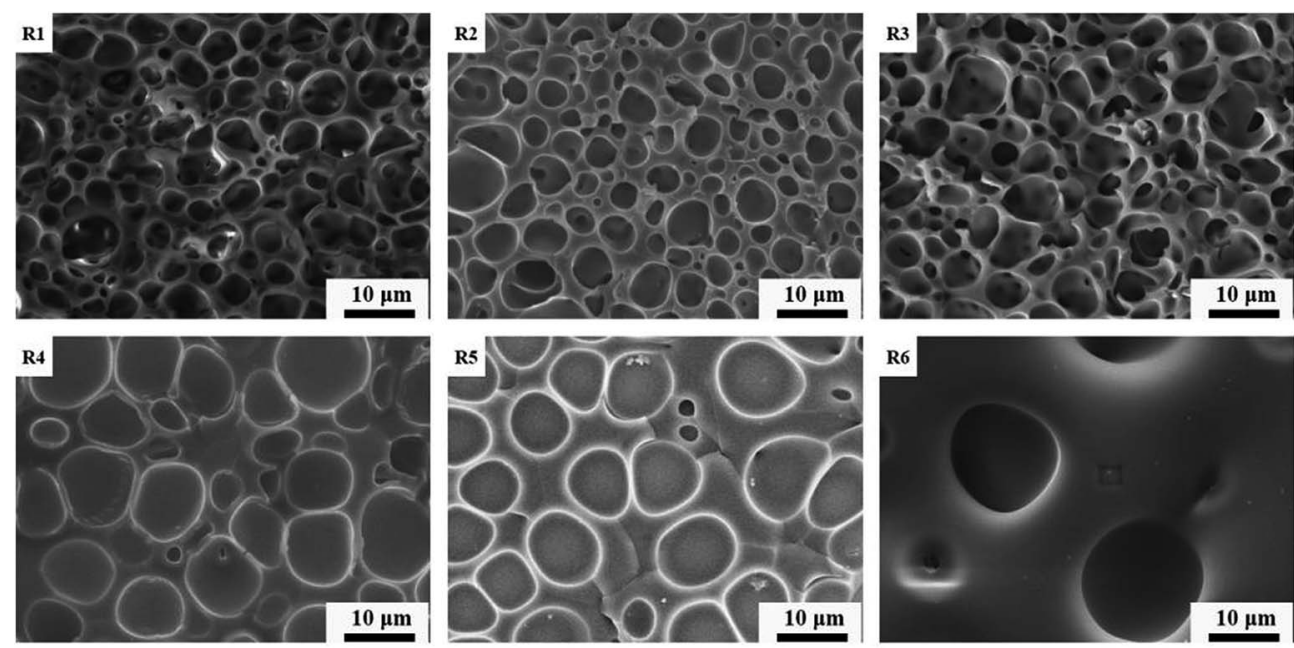

Fig. 4 SEM micrographs of the polymer morphologies of films R1-R6. 

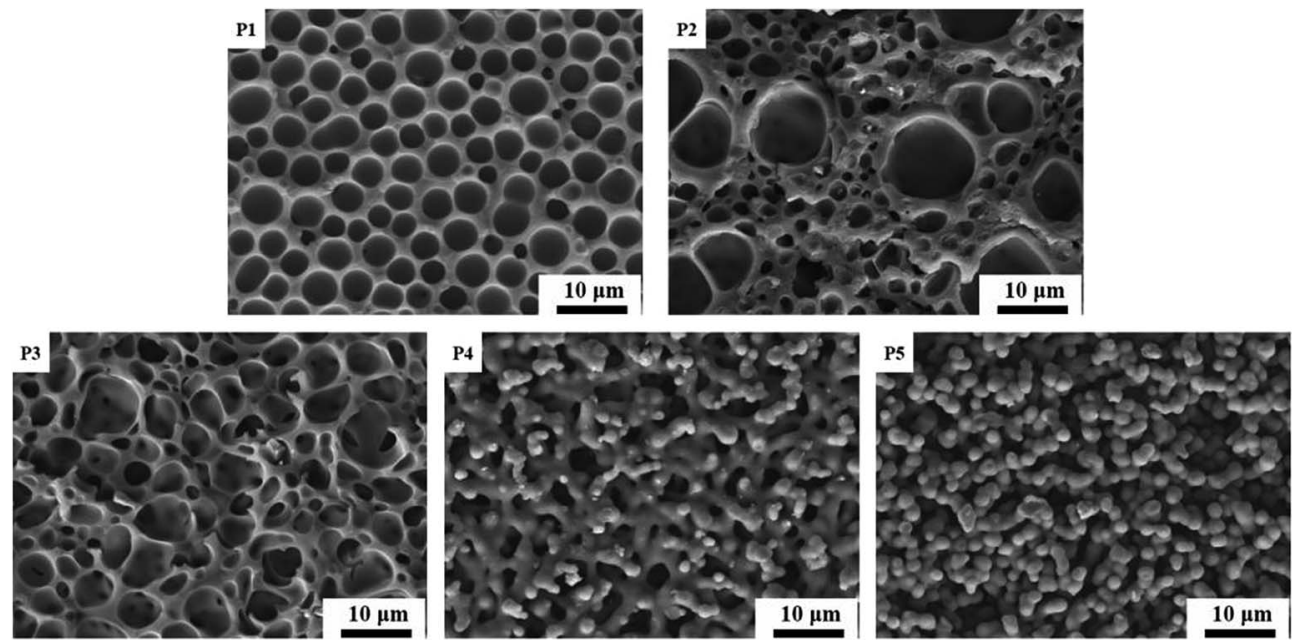

Fig. 5 SEM micrographs of the polymer morphologies of films P1-P5.

polymer matrices in the films were examined by scanning electron microscopy (SEM, HITACHI S-4800) after the LCs were removed. The films were cut into small strips and soaked in cyclohexane for two weeks at room temperature to extract the LC molecules, after which, they were dried for 4 hours at $353.15 \mathrm{~K}$ under vacuum, sputtered with gold coating and observed by SEM.

\section{Results and discussion}

\subsection{Light scattering theory}

As described in Li's study, ${ }^{30}$ three appropriate approaches for light scattering in PDLC films are demonstrated: the RayleighGans (RG) approximation, the anomalous diffraction (AD) approach and the geometrical optics (GO) approach. When the
(A)

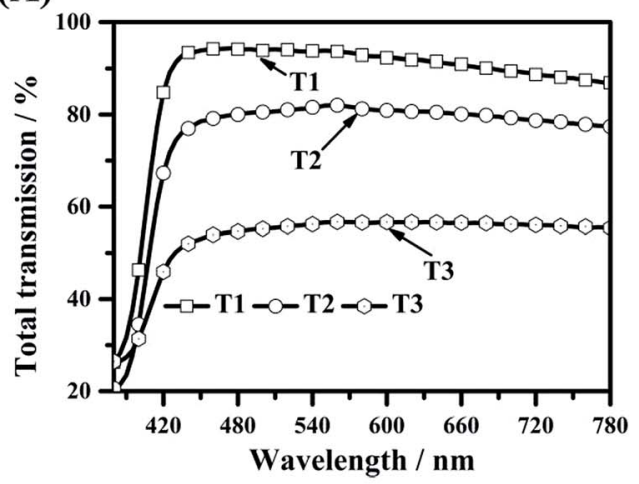

(C)

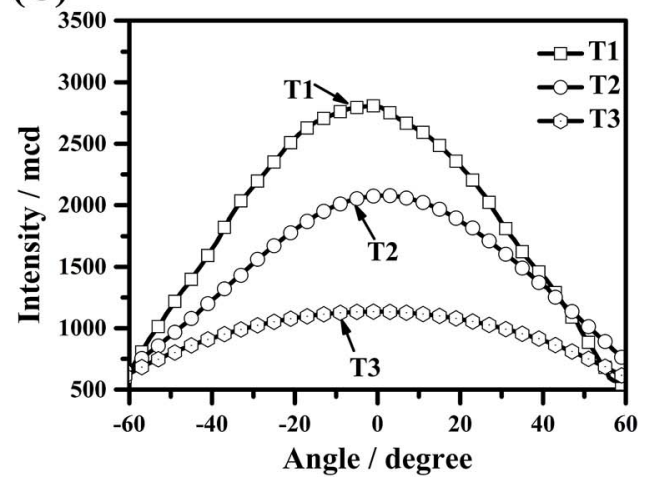

(B)

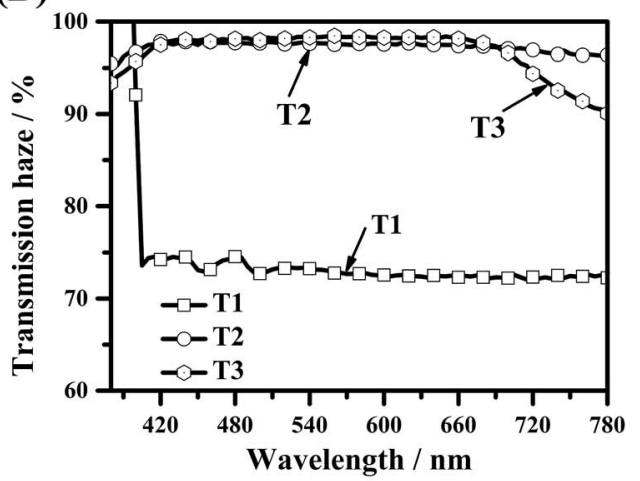

(D)

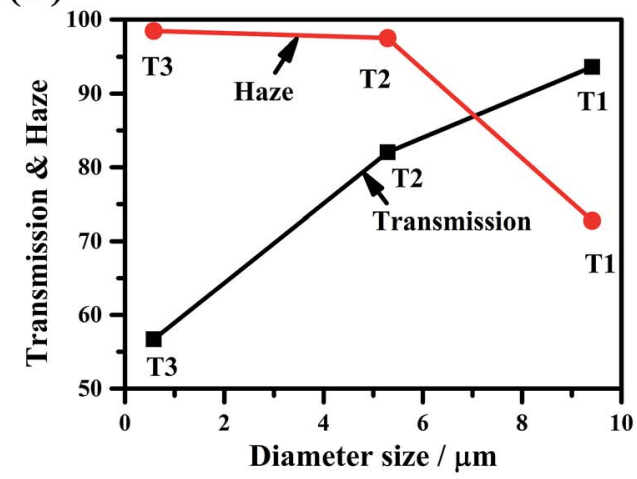

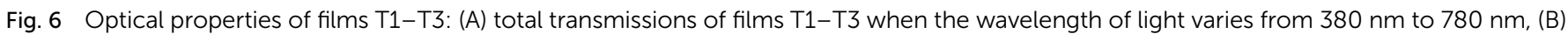

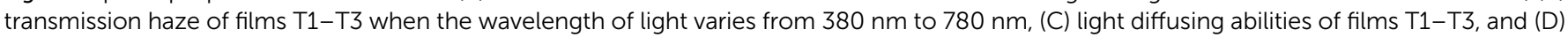
the relationship between transmission \& haze and diameter size of the LC droplets when the wavelength of light is 560 nm. 
average size of the LC droplets is smaller than the wavelength of light (the diameter of LC droplets $D<\lambda$ ), the RG approximation is applied in the film and the light scattering intensity is as $\tau \propto$ $D^{3} / \lambda^{4}$. When the average size of the LC droplets is larger than the wavelength of light, light scattering can be depicted with the AD approximation, and the light scattering intensity is $\tau \propto D / \lambda^{2}$. If the LC droplets are very large, the light scattering is described by the GO approximation, and the light scattering intensity is $\tau$ $\propto 1 /\left(D \lambda^{n}\right)(0 \leq n<4)$.

\subsection{SEM morphology}

The polymer microstructures of the films which were respectively cured at $313.15 \mathrm{~K}, 333.15 \mathrm{~K}$ and $353.15 \mathrm{~K}$ were investigated in order to confirm the effect of curing temperature on the composites. In Fig. 2, it can be seen that the number of LC domains improves as the curing temperature is increased from $313.15 \mathrm{~K}$ to $353.15 \mathrm{~K}$, and the diameters of LC droplets are $9.41 \mu \mathrm{m}, 5.29 \mu \mathrm{m}$ and $0.58 \mu \mathrm{m}$ respectively in films T1-T3. In this situation, the GO approximation is applied in films T1T3 and the optical properties of films T1-T3 varied a lot.

An illustration of the variation of the polymeric microstructures in the films L1-L5 as the LC concentration increasing is shown in Fig. 3. As the concentration of LC was increased from $30 \mathrm{wt} \%$ to $50 \mathrm{wt} \%$ in films L1-L3, all of the polymeric microstructures appeared to be polymer networks, in which the diameters of the LC droplets were $4.99 \mu \mathrm{m}$ and $5.29 \mu \mathrm{m}$ respectively in film L1 and film L3. Additionally, the LC droplets in film L2 had different sizes, with diameters of $2.85 \mu \mathrm{m}$ for the bigger droplets, while the smaller ones were $0.71 \mu \mathrm{m}$. However, the polymeric microstructures in films L4 and L5 appeared to be polymer microballs, of which the diameter of the microballs in film L4 was $10.00 \mu \mathrm{m}$ and that in film L5 was $4.99 \mu \mathrm{m}$. According to the size of the LC droplets or the polymeric microballs, the GO approximation is applicable for films L2 and L3, while the GO approximation is not applicable for the PDLC film when the content of LC is lower than that in film L2 or higher than that in film L3.

By fixing the curing temperature and the LC content in the preparation of the films, the polymeric microstructures in films R1-R6, with an increasing content of E-51 and as shown in Fig. 4, were investigated because the composition of monomers is critical to the properties of the films. With the increase in the concentration of epoxy resin E-51, the viscosity of the composites increased so that the LCs did not have enough time to disperse, and the size of LC droplets increased. When the ratio of E-51 and RDE was lower than 1, the microstructures of the polymer matrix were similar and the diameters of the LC droplets were $4.29 \mu \mathrm{m}, 5.71 \mu \mathrm{m}$, and $5.29 \mu \mathrm{m}$ in films R1-R3, respectively. When the ratio was over 1 , the average sizes of the LC droplets in films R4-R6 continuously increased, and the diameters of the LC droplets were $10.00 \mu \mathrm{m}, 11.43 \mu \mathrm{m}$ and 12.85
(A)

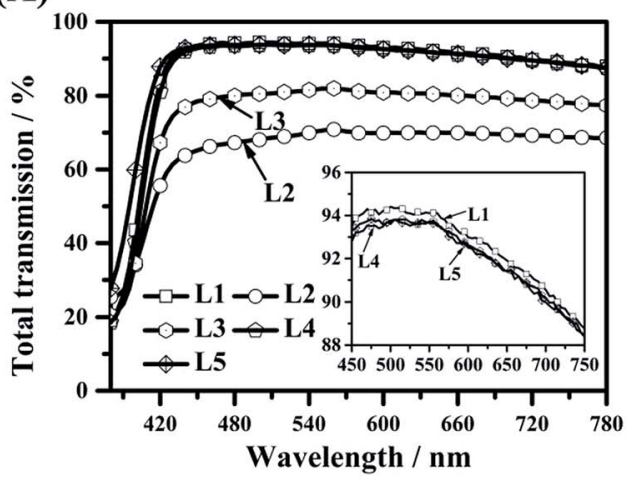

(C)

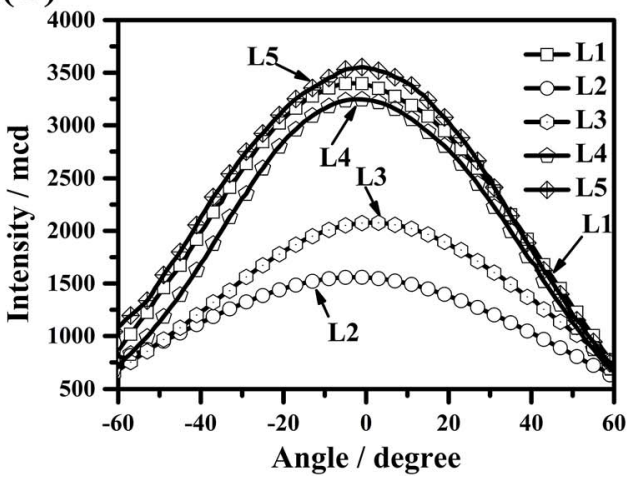

(B)

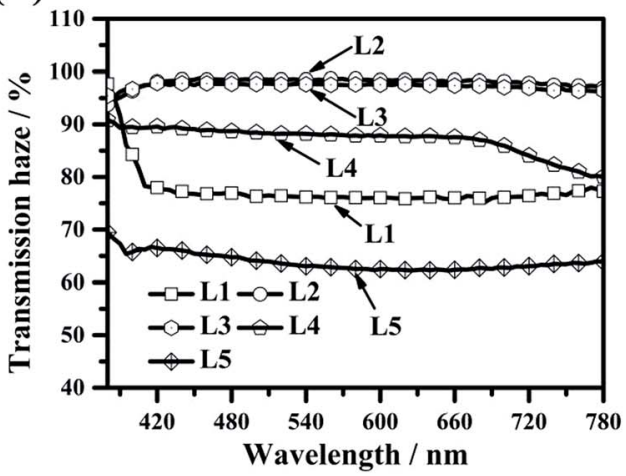

(D)

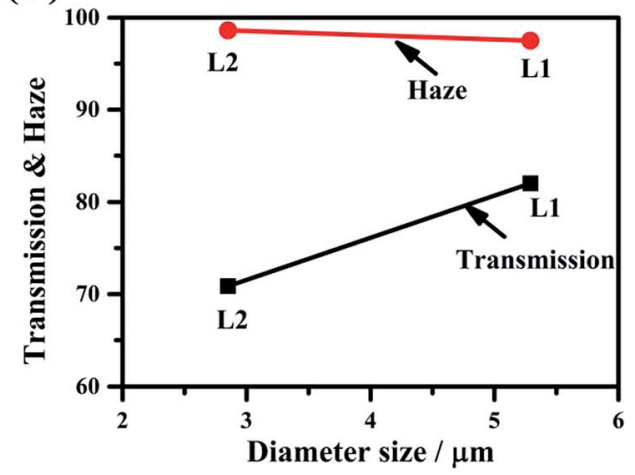

Fig. 7 Optical properties of films L1-L5: (A) total transmissions of films L1-L5 when the wavelength of light varies from $380 \mathrm{~nm}$ to $780 \mathrm{~nm}$, (B) transmission haze of films L1-L5 when the wavelength of light varies from $380 \mathrm{~nm}$ to $780 \mathrm{~nm}$, (C) light diffusing abilities of films $L 1-L 5$, and (D) the relationship between transmission \& haze and diameter size of LC droplets when the wavelength of light is $560 \mathrm{~nm}$. 
$\mu \mathrm{m}$ in films R4-R6 respectively. Due to the increase of LC droplet size with the increasing content of E-51, GO theory was applicable for the films, and the optical properties are discussed in detail in next section.

Similarly, when the curing temperature, the LC content and the composition of the monomers were fixed, the effect of the content of the curing agent, TTMP, on the polymeric microstructures in films P1-P5 was studied. As shown in Fig. 5, the microstructures of the polymers in films P1-P5 are divided into three types: polymer networks in films $\mathrm{P} 1-\mathrm{P} 3$, polymer balls in film P5 and a combined polymer morphology of polymer networks and polymer balls in film $\mathrm{P} 4$. When there is no thiol in the monomer mixture, the size of the LC droplets is uniform, and in film P1 the diameter of the droplets is $5.33 \mu \mathrm{m}$. When initially relatively low amounts of thiol are added, the average size of the LC droplets increases as demonstrated in film P2. Additionally, there are two different sizes of droplets and the diameters are $14.00 \mu \mathrm{m}$ (the bigger one) and $1.99 \mu \mathrm{m}$ (the smaller one), respectively. When the content of thiol is comparable to that of PA, polymer balls are formed, and a transient state is presented in film $\mathrm{P} 4$, where the diameter of the polymer balls is $2.67 \mu \mathrm{m}$ and that of the LC droplets in the polymer networks is $1.99 \mu \mathrm{m}$. Furthermore, only the polymer ball morphology is present in film P5, with the highest content of thiol in the monomer mixture, where the diameter of the polymer microballs is $2.33 \mu \mathrm{m}$. Thus, GO theory is adequate for the system, and the optical properties of the films with the three types of polymeric microstructures will be discussed later.

\subsection{Optical properties}

As is shown in Fig. 6(A) and (B), the trend of total transmission presents as $\mathrm{T} 1>\mathrm{T} 2>\mathrm{T} 3$ and the trend in transmittance haze presents as $\mathrm{T} 3>\mathrm{T} 2>\mathrm{T} 1$. As presented in Fig. 6(C), the trend in the diffusing abilities of the films is consistent with that of haze. Film T3 possesses a high diffusing ability and the maximum light intensity is lower than 1000 mcd, however film T2 possesses a high light intensity while the diffusing ability is not excellent. Considering the high diffusing ability and the high light intensity, the curing temperature at $333.15 \mathrm{~K}$ is applicable. In order to investigate the relationship between the diameter size of the LC droplets and the optical properties, the transmissions and hazes of the T1-T3 films at $660 \mathrm{~nm}$ are shown in Fig. 6(D). Due to the size of the LC droplets, GO theory is applicable in films T1-T3 and the light diffusing ability is in inverse proportion to the droplet size, as seen in Fig. 6(D). Herein, the transmission decreases and the haze increases with the increase in the size of the LC droplets, which matches the GO approximation.

As shown in Fig. 7(A) and (B), the trend of total transmission presents as L1 $>\mathrm{L} 5>\mathrm{L} 4>\mathrm{L} 3>\mathrm{L} 2$ and the trend in transmittance haze presents as $\mathrm{L} 2>\mathrm{L} 3>\mathrm{L} 4>\mathrm{L} 1>\mathrm{L} 5$. When the content of $\mathrm{LC}$
(A)

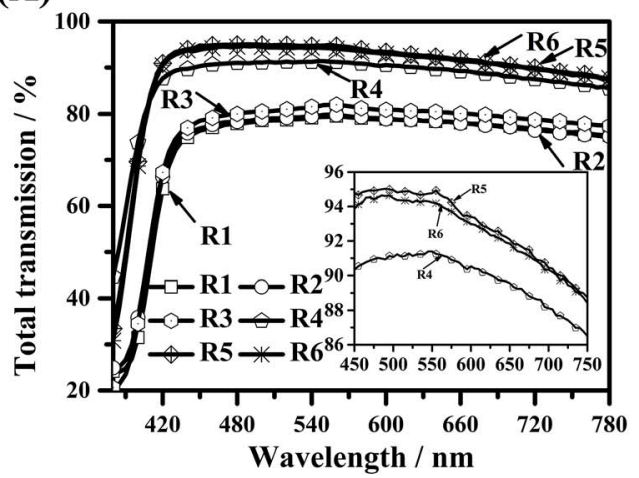

(C)

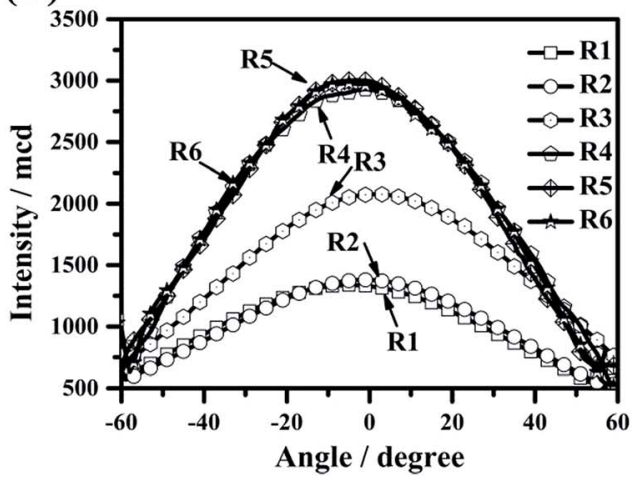

(B)

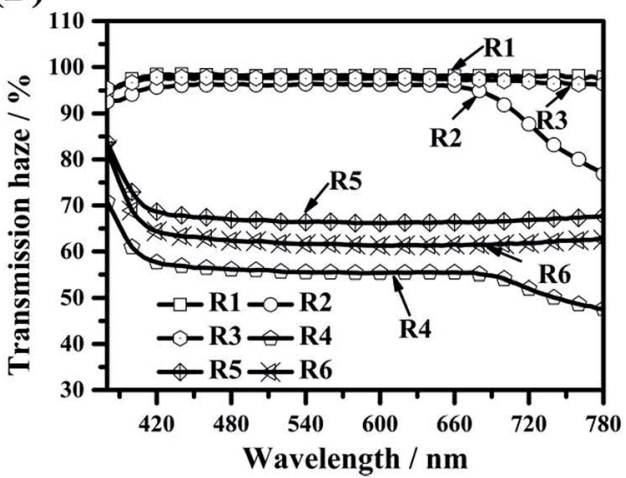

(D)

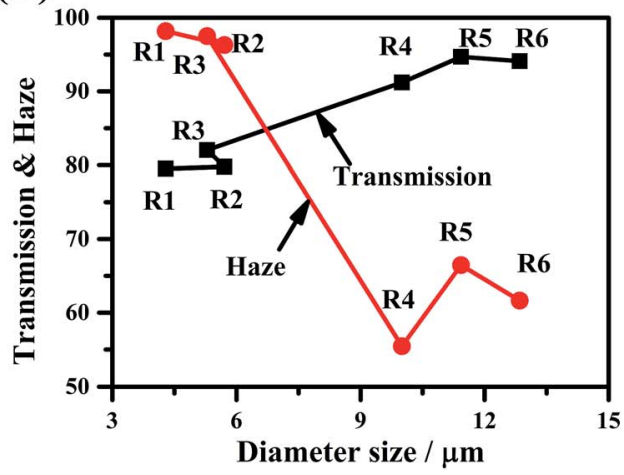

Fig. 8 Optical properties of films R1-R6: (A) total transmissions of films R1-R6 when the wavelength of light varies from $380 \mathrm{~nm}$ to $780 \mathrm{~nm}$, (B) transmission haze of films R1-R6 when the wavelength of light varies from $380 \mathrm{~nm}$ to $780 \mathrm{~nm}$, (C) light diffusing abilities of films R1-R6, (D) and the relationship between transmission \& haze and diameter size of LC droplets when the wavelength of light is $560 \mathrm{~nm}$. 
is $30 \mathrm{wt} \%$, the light scattering is very weak because there are few LC droplets dispersed in the polymer substrate, and this is presented in Fig. 7(C). In films L2 and L3, GO theory is applied, and the relationship between the optical properties and the diameter size is presented in Fig. 7(D). The experimental results are also consistent with the theory, where the haze of film L2 is the highest due to the smallest LC droplet size. When the content of LC is over $50 \mathrm{wt} \%$, owing to polymer microballs formed in films L4 and L5, and due to the high transmission of LCs, the transmission of the film increases and haze decreases as LC content increases. As is shown in Fig. 6(C), films L1-L5 all present excellent diffusion abilities. Film L2 presents low transmittance due to the attenuation of transmittance with the increase in light scattering. Due to high transmission and excellent diffusing ability, the LC content at $50 \mathrm{wt} \%$ is appropriate for the system.

As shown in Fig. 8(A) and (B), the trend of total transmission presents as $\mathrm{R} 5>\mathrm{R} 6>\mathrm{R} 4>\mathrm{R} 3>\mathrm{R} 2>\mathrm{R} 1$, and the trend in transmittance haze presents as R1 $>\mathrm{R} 3>\mathrm{R} 2>\mathrm{R} 5>\mathrm{R} 6>\mathrm{R} 4$. According to the sizes of the LC droplets in films R1-R6, the GO approximation is satisfied by the system. As is depicted in Fig. 8(C), haze generally decreases and transmittance increases as the size of LC droplets develops, which conforms to the GO approximation. In addition, the hazes of films R5 and R6 are higher than that of film R4, because the diameter of the LC droplets is over $10.00 \mu \mathrm{m}$. As an exception of the GO approximation, after light propagates through the films, the transmitted light also interferes with itself, and then haze increases without decreasing transmission. As the number of LC droplets is small in film R6, the haze of film R6 is less than that of film R5. Furthermore, films R1 and R2 both display good diffusing abilities (shown in Fig. 7(C)), and their visible transmittances are lower than $90 \%$ while their maximum light intensities are both low. Consequently, the appropriate weight ratio of E-51 and RDE is $1: 3$ to achieve a high transmission and high diffusing ability.

Herein, the trend of total transmissions of films P1-P5 is $\mathrm{P} 4>\mathrm{P} 1>\mathrm{P} 3>\mathrm{P} 5>\mathrm{P} 2$ and the trend in the transmittance haze of films P1-P5 is P5 $>$ P3 $>$ P2 $>$ P1 > P4. In films P1-P3, the LC droplets are dispersed in polymer networks, due to their micrometer scale, and the GO approximation is applicable in the system. The transmission of the films decreases with the decrease of the size of LC droplets, which is described in Fig. 9(D). As there are much smaller LC droplets in film P2, transmission of film P2 is lower than that of film P3. While the morphology of the polymer is a mixture of polymer balls and polymer networks in film P4, scattering in P4 slightly decreases and high transmittance is obtained. As the polymer morphology is ball-shape in film P5, light scattering reaches the highest value, due to the coherent effect of light scattering of the anisotropic LCs and the isotropic polymers. Films P1-P5 all present good diffusion abilities
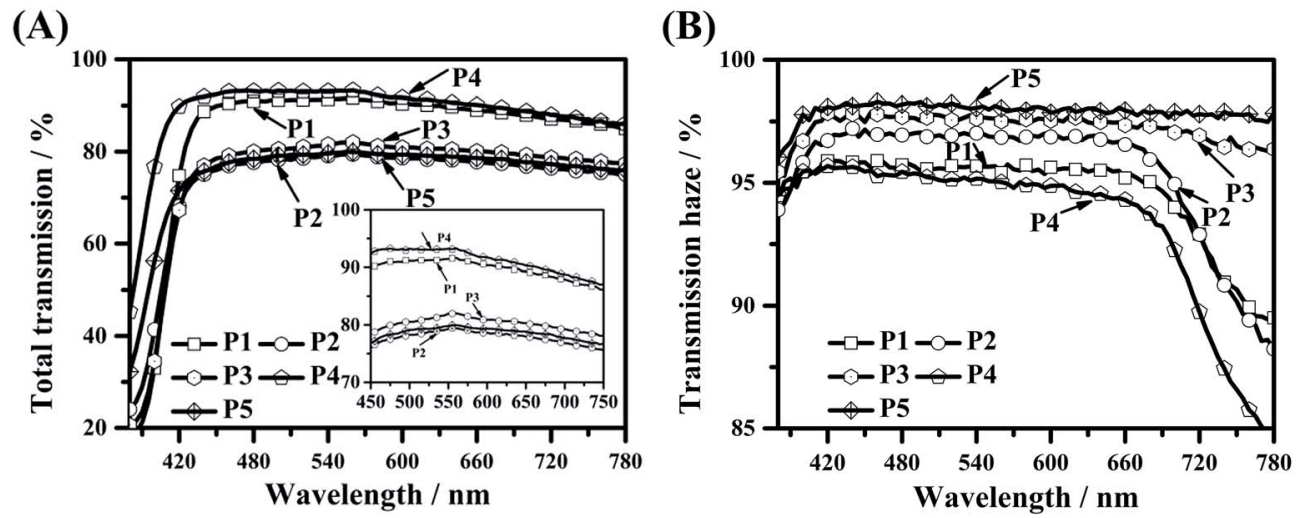

(C)

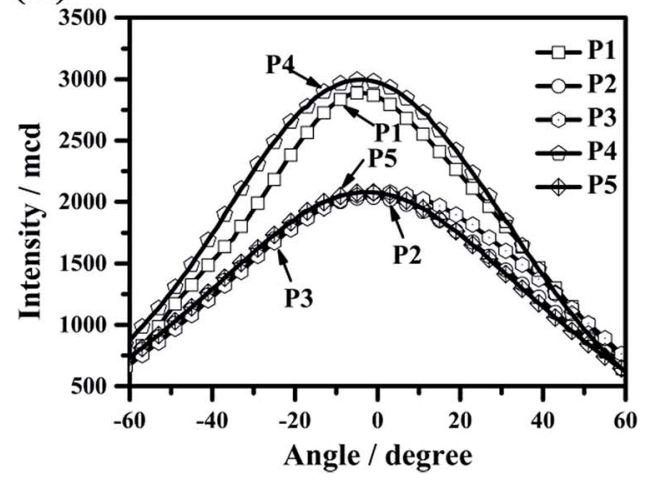

(D)

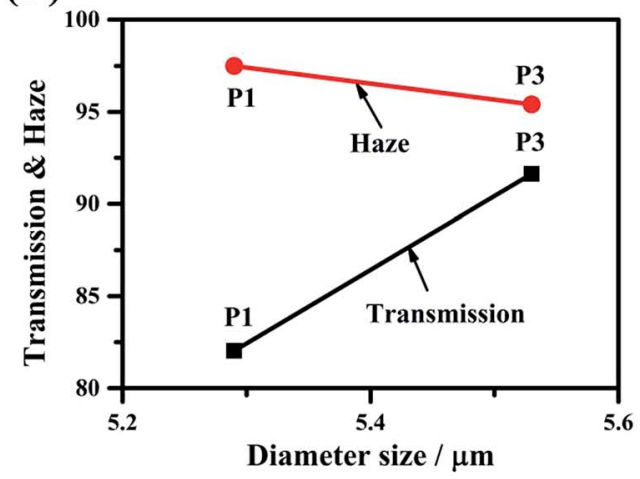

Fig. 9 Optical properties of films P1-P5: (A) total transmissions of films P1-P5 when the wavelength of light varies from $380 \mathrm{~nm}$ to $780 \mathrm{~nm}$, (B) transmission haze of films P1-P5 when the wavelength of light varies from $380 \mathrm{~nm}$ to $780 \mathrm{~nm}$, (C) light diffusing abilities of films P1-P5, and (D) the relationship between transmission \& haze and diameter size of LC droplets when the wavelength of light is $560 \mathrm{~nm}$. 
(see Fig. 9(C)), and taking the transmission into consideration, film $\mathrm{P} 4$ is promising for application in light diffusers in LCDs.

\section{Conclusions}

It is clear that film P4 has high transmittance (>93\%) and high haze $(>95 \%)$, due to the combined special polymer microstructures in the film, composed of both polymer networks and polymer balls. The film can be applied as a novel optical diffuser, which will give great potential for application in LCDs, OLEDs and other display applications.

In summary, the thiol, TTMP, is an effective accelerator for preparing PDLC films that rely on an epoxy resin-polyamine system, and the presented film posesses high transmittance and transmittance haze with the mass ratio of $3: 1$ (thiol to PA). Additionally, it takes just 1 hour to cure these films, largely shortening the curing process, which provides high potential for application in the novel light diffuser field.

\section{Conflicts of interest}

No potential conflict of interest was reported by the authors.

\section{Acknowledgements}

This work was supported by the National Natural Science Foundation of China (NSFC) (Grant no. 51333001, 51573006 and 51573003), the Key International Cooperation Project (Grant no. 51720105002) and NSFC International Cooperation and Exchanges Projects (Grant no. 51561135014).

\section{References}

$1 \mathrm{~J}$. Hu, Y. Zhou and T. Zhang, The novel optical diffusers based on the fillers of boehmite hollow microspheres, Mater. Lett., 2014, 136, 114-117.

2 J. Zhu, Y. Liu, S. Shen and J. Wu, Fabrication of engineered particle-doped light diffuser with a soft transparent mold of UV-curable polymer, Opt. Mater., 2017, 73, 234-240.

3 W. Suthabanditpong, M. Tani, C. Takai, M. Fuji, R. Buntem and T. Shirai, Facile fabrication of light diffuser films based on hollow silica nanoparticles as fillers, Adv. Powder Technol., 2016, 27, 454-460.

4 G. Kang, K. Bae, M. Nam, D.-H. Ko, K. Kim and W. J. Padilla, Broadband and ultrahigh optical haze thin films with selfaggregated alumina nanowire bundles for photovoltaic applications, Energy Environ. Sci., 2015, 8, 2650-2656.

5 Z. Zhao, J. Qiu, Y. Xiong, X. Liu, J. Shen and S. Guo, In situ preparation of core-shell-like scatterers and their effects on optical and mechanical properties of PC-matrix light diffusing materials, Mater. Des., 2017, 115, 355-363.

6 H.-G. Park and D.-Y. Khang, High-performance light diffuser films by hierarchical buckling-based surface texturing combined with internal pores generated from physical gelation induced phase separation of binary polymer solution, Polymer, 2016, 99, 1-6.
7 S. Guo, S. Zhou, H. Li and B. You, Light diffusing films fabricated by strawberry-like $\mathrm{PMMA} / \mathrm{SiO}_{2}$ composite microspheres for LED application, J. Colloid Interface Sci., 2015, 448, 123-129.

8 S. Song, Y. Sun, Y. Lin and B. You, A facile fabrication of light diffusing film with LDP/polyacrylates composites coating for anti-glare LED application, Appl. Surf. Sci., 2013, 273, 652660.

$9 \mathrm{~J} . \mathrm{Fu}, \mathrm{Y}$. Wang and Y. Zhu, Broadband and high diffuse reflectivity of hollow mesoporous silica nanospheres and their UV light shielding ability for light-labile peroxides, Mater. Lett., 2015, 153, 89-91.

$10 \mathrm{~J} . \mathrm{Hu}$ and $\mathrm{Y}$. Zhou, The properties of nano $\left(\mathrm{ZnO}-\mathrm{CeO}_{2}\right)$ (apolysiloxane core-shell microspheres and their application for fabricating optical diffusers, Appl. Surf. Sci., 2016, 365, 166-170.

$11 \mathrm{~J} . \mathrm{Hu}, \mathrm{Y}$. Zhou and X. Sheng, Optical diffusers with enhanced properties based on novel polysiloxane@ $\mathrm{CeO}_{2} @ P M M A$ fillers, J. Mater. Chem. C, 2015, 3, 2223-2230.

$12 \mathrm{~J} . \mathrm{Hu}, \mathrm{Y}$. Zhou and X. Sheng, Hydrothermal synthesis of ZnO@polysiloxane microspheres and their application in preparing optical diffusers, RSC Adv., 2015, 5, 17064-17069.

13 W. Suthabanditpong, C. Takai, M. Fuji, R. Buntem and T. Shirai, Improved optical properties of silica/UV-cured polymer composite films made of hollow silica nanoparticles with a hierarchical structure for light diffuser film applications, Phys. Chem. Chem. Phys., 2016, 18, 16293-16301.

14 A. Colombo, F. Tassone, F. Santolini, N. Contiello, A. Gambirasio and R. Simonutti, Nanoparticle-doped large area PMMA plates with controlled optical diffusion, J. Mater. Chem. C, 2013, 1, 2927-2934.

15 S. Lih Yeh, A study of light scattered by surface-relief holographic diffusers, Opt. Commun., 2006, 264, 1-8.

16 A. Ghosh and T. K. Mallick, Evaluation of colour properties due to switching behaviour of a PDLC glazing for adaptive building integration, Renewable Energy, 2018, 120, 126-133.

17 H. Butt, K. M. Knowles, Y. Montelongo, G. A. J. Amaratunga and T. D. Wilkinson, Devitrite-Based Optical Diffusers, ACS Nano, 2014, 8, 2929-2935.

18 K. M. Knowles, H. Butt, A. Batal, A. Sabouri and C. J. Anthony, Light scattering and optical diffusion from willemite spherulites, Opt. Mater., 2016, 52, 163-172.

19 H. Butt, A. K. Yetisen, A. A. Khan, K. M. Knowles, M. M. Qasim, S. Hyun Yun and T. D. Wilkinson, Electrically Tunable Scattering from Devitrite-Liquid Crystal Hybrid Devices, Adv. Opt. Mater., 2017, 5, 1600414.

20 T. Alqurashi, A. Alhosani, M. Dauleh, A. K. Yetisen and H. Butt, Laser inscription of pseudorandom structures for microphotonic diffuser applications, Nanoscale, 2018, 10, 7095-7107.

21 M. Elsherif, M. Umair Hassan, A. K. Yetisen and H. Butt, Glucose Sensing with Phenylboronic Acid Functionalized Hydrogel-Based Optical Diffusers, ACS Nano, 2018, 12, 2283-2291. 
22 J. M. Miranda-Muñoz, G. Lozano and H. Míguez, Design and Realization of a Novel Optically Disordered Material: A Demonstration of a Mie Glass, Adv. Opt. Mater., 2017, 5, 1700025.

23 S.-W. Oh, J.-M. Baek, J. Heo and T.-H. Yoon, Dye-doped cholesteric liquid crystal light shutter with a polymer dispersed liquid crystal film, Dyes Pigm., 2016, 134, 36-40.

24 Q. Y. Meng, H. Cao, M. Kashima, H. J. Liu and H. Yang, Effects of the structures of epoxy monomers on the electrooptical properties of heat-cured polymer dispersed liquid crystal films, Liq. Cryst., 2010, 37, 189.

25 T. Zhang, M. Kashima, M. Zhang, F. Liu, P. Song, X. Zhao, C. Zhang, H. Cao and H. Yang, Effects of the functionality of epoxy monomer on the electro-optical properties of thermally-cured polymer dispersed liquid crystal films, RSC Adv., 2012, 2, 2144-2148.

26 Y. Gao, P. Song, T. Zhang, W. Yao, H. Ding, J. Xiao, S. Zhu, H. Cao and H. Yang, Effects of a triethylamine catalyst on curing time and electro-optical properties of PDLC films, RSC Adv., 2013, 3, 23533-23538.

27 S. J. Chang, C. M. Lin and A. Y. G. Fuh, Studies of polymer ball type polymer dispersed liquid crystal films, Liq. Cryst., 1996, 21, 19-23.

28 A. Y.-G. Fuh, C.-R. Lee and Ya-H. Ho, Thermally and electrically switchable gratings based on polymer-ball-type polymer-dispersed liquid-crystal films, Appl. Opt., 2002, 41, 4585-4589.

29 J. Jiang, G. Mcgraw, R. Ma, J. Brown and D. Yang, Selective scattering polymer dispersed liquid crystal film for light enhancement of organic light emitting diode, Optic Express, 2017, 25, 3327-3335.

30 W. Li, Z. Cheng, G. Pan, et al., Effects of the mixture composition on the microstructure of polymer matrix and light scattering properties of liquid crystal/photopolymerizable monomers composites, Opt. Mater., 2008, 31, 434-439. 